\title{
Prevalence of kala-azar infection in Pokot county, Amudat district, Northeastern Uganda
}

\author{
Walter D. Odoch ${ }^{1}$, Joseph O. Olobo ${ }^{2}$ \\ ${ }^{1}$ School of Public Health, Makerere University College of Health Sciences, Kampala, Uganda \\ ${ }^{2}$ School of Biomedical Sciences, Makerere University College of Health Sciences, Kampala, Uganda \\ Email: walodoch@yahoo.com
}

Received 5 September 2013; revised 5 October 2013; accepted 12 October 2013

Copyright (C) 2013 Walter D. Odoch, Joseph O. Olobo. This is an open access article distributed under the Creative Commons Attribution License, which permits unrestricted use, distribution, and reproduction in any medium, provided the original work is properly cited.

\begin{abstract}
Introduction: Visceral leishmaniasis (kala-azar) caused by Leishmania donovani and transmitted by the sand-fly Phlebotomus martini is endemic in certain foci in north-eastern Uganda where it is thought to be confined to Pokot county, Amudat district. Amudat hospital records (April 1998-March 1999) indicated that kala-azar accounted for about $17 \%$ of hospital in-patients. However the actual prevalence of kalaazar infection in the community in Pokot county is unknown. This lack of information limits efforts geared towards its control. Objective: To determine the prevalence of kala-azar infection in Pokot county. Methods: A cross-sectional study was conducted in Pokot county in March 2010. The study participants were $\geq 5$ years and were randomly selected from the age and sex strata in the chosen clusters. A questionnaire that elicited demographic profiles of participants was used for data collection. Standard procedure for direct agglutination test using blood samples collected from participants on blotting papers was performed. Data was entered in EPIINFO 3.3 and exported to STATA 10, where descriptive statistics were generated. Results: The overall prevalence of kalaazar infection in Pokot county was $17.2 \%$ but the prevalence of symptomatic infection in the community was $2.5 \%$. The ratio of symptomatic to asymptomatic kala-azar was 1:6. Loroo sub-county had the highest prevalence of kala-azar infection followed by Karita and Amudat sub-counties at 31.9\%, $14.6 \%$ and $5.3 \%$, respectively. Conclusion: With kala-azar infection prevalence at $17.2 \%$ in the community, there is an urgent need to institute control program spearheaded by ministry of health, in the region. Furthermore, recent reports of cases from other districts within the region, the heterogeneous distribution of infection within the
\end{abstract}

county and the current risk factors, including the role of animals in kala-azar transmission in this area need to be evaluated.

Keywords: Kala-Azar; Pokot; Amudat; Prevalence; Direct Agglutination Test

\section{INTRODUCTION}

Kala-azar or visceral leishmaniasis (VL) is the most serious form of leishmaniasis and is fatal if not treated. It is caused by protozoan parasites that belong to the Leishmania donovani complex comprising of $L$. donovani and L. infantum [1]. Transmission is through the bite of female sand-flies belonging to the genus Phlebotomus and Lutzomyia in the Old World and New World respectively. The disease is endemic in about 62 countries in the tropical, sub-tropical and southern Europe and 200 million people are at risk of infection [2]. More than $90 \%$ of VL cases occur in India, Bangaladesh, Nepal, Sudan, South Sudan, Brazil and Ethiopia [3]. East Africa forms the second largest focus of VL in the world, and the disease is largely found in underdeveloped communities [4]. Infection with $L$. donovani can be asymptomatic, and these cases are considered as potential reservoirs of further transmission [5]. Actual estimation of asymptomatic VL in endemic areas has been assessed by serological methods and Leishmanin Skin Test (LST) [5], and has given reliable but varying ratios of asymptomatic to symptomatic cases in the different regions.

In Uganda, kala-azar infection was first described in 1950's [6]. It was thought to be endemic only in Pokot county, Amudat district [7], where it is locally known as termes (referring to huge spleen, one of the main clinical manifestation in this area). However, the 2010 Amudat hospital report (unpublished) indicates that kala-azar pa- 
tients have come from other districts as well in the recent time.

The prevalence of kala-azar in the Pokot community in Pokot county is not known. Such epidemiological information is vital for the undertaking of control programs. Therefore, this community-based prevalence study was conducted to provide preliminary information for focused planning for the control of kala-azar infection in Pokot county.

\section{METHOD}

This was an observational cross-sectional study conducted in March 2010, in Pokot county, which is a semiarid area in north-eastern Uganda lying between the mountains Kadam and Moroto and the hills along the Uganda-Kenya border. The people basically live a semi-nomadic lifestyle. The homesteads are organized into groups of family units, living within mud walls and grass thatched roofed houses encircled by thorny fencing called $m a$ nyatta.

Institutional and national ethical clearance was obtained before initiation of the study. A written informed consent was obtained from each adult participant, while a parent or guardian consented on behalf of a participant who was under 18 years of age.

The participants were sampled in a multistage cluster sampling with age and sex stratification in the final cluster stage. The final cluster was the manyatta and by using a formula of cluster surveys, a total of 12 clusters (many$a t t a)$ were determined for this study [8].

$$
C=\frac{p(1-p) D}{s^{2} b}
$$

where,

$C$ : number of clusters selected

$p$ : estimated prevalence of kala-azar in Pokot county

$D$ : Design effect and 1.3 was used in this study because it has been used in similar study design of kalaazar community survey in Brazil [9].

$b$ : number of respondent per cluster and 24 was used in this study.

$s$ : standard error,

$$
s=\frac{\text { CI width }}{C_{\alpha}}
$$

CI width: width of the desired confidence interval of 0.05

$C_{\alpha}$ : the value from the standard normal curve corresponding to the accepted alpha value of 1.96.

Initially, 2 parishes were randomly selected by use of table of random numbers from each of the 3 sub-counties in Amudat district (sub-counties consist of three or four parishes). Two manyatta were then selected from each of the selected parishes (also by use of table of random numbers), thus a total of 288 participants were enrolled for the study. Parishes have between 5 and 7 manyatta. In order to ensure age and sex representation, the members of the selected manyatta were stratified into sex and age groups (Table 1). Available information (Amudat District Development Plan-unpublished) at the district planning office indicates relatively similar population sizes in our age strata and the ratio of men to women in the county is close to one (i.e. 0.98). Therefore sampling with probability proportional to size was not used in the sampling of the clusters or strata.

Independent variables included socio-demographics and kala-azar treatment history. Dependent variables, included kala-azar sero-status as determined by direct agglutination test (DAT) performed on the participant blood sample and clinical features. These were used to categorize the participants into negative, symptomatic, asymptomatic.

Blood samples from participants were collected by finger pricks blotted onto filter paper Whatmans No. 3 and allowed to air dry, forming a Dry Blood Spot (DBS). The DAT was performed at Amudat hospital laboratory, as originally described [10]. Briefly, disks containing blood were punched out of the filter paper and eluted overnight in $0.9 \% \mathrm{NaCl}$ solution containing $0.8 \% \beta$-mercaptoethanol

Table 1. Chi square test for the DAT results disaggregated by

\begin{tabular}{|c|c|c|c|c|c|}
\hline Variable & $\begin{array}{c}\text { Proportion } \\
\text { of the DAT } \\
\text { positive } \\
\text { participant }\end{array}$ & $\begin{array}{c}\text { Percentage } \\
\text { of DAT } \\
\text { positivity }\end{array}$ & Df & $\mathbf{X}^{2}$ & p-value \\
\hline \multicolumn{6}{|l|}{ Sub-county } \\
\hline Amudat (ref) & $5 / 95$ & 5.3 & & & \\
\hline Loroo & $30 / 94$ & 31.9 & 1 & 14.25 & $<0.001^{*}$ \\
\hline Karits & $14 / 96$ & 14.6 & 1 & 21.35 & $<0.001^{*}$ \\
\hline \multicolumn{6}{|l|}{ Sex } \\
\hline Female (ref) & $21 / 144$ & 14.6 & & & \\
\hline Male & $28 / 141$ & 19.9 & 1 & 1.39 & 0.238 \\
\hline \multicolumn{6}{|l|}{ Age group } \\
\hline $05-10$ (ref) & $15 / 92$ & 16.3 & & & \\
\hline $11-15$ & $6 / 48$ & 12.5 & 1 & 0.08 & 0.783 \\
\hline $16-25$ & $13 / 74$ & 17.6 & 1 & 0.89 & 0.345 \\
\hline $26-35$ & $6 / 30$ & 20.0 & 1 & 0.01 & 0.921 \\
\hline $36-60$ & $9 / 41$ & 22.0 & 1 & 0.19 & 0.667 \\
\hline
\end{tabular}
sub-county, sex and age group.

*Statistically significant. 
in wells of V-shaped microtitre plates (Greiner Laboratories, Alphen, The Netherlands). Two-fold dilution series of the sera were made, starting at a dilution of 1:100 up to a maximum serum dilution of 1:102,400. Freezedried DAT antigen, L. donovani promastigotes (Royal Tropical Institute, Amsterdam Netherlands) was reconstituted with physiological saline according to the instructions. Fifty $\mu \mathrm{l}$ of DAT antigen solutions (concentration of $5 \times 10^{7}$ parasites per $\mathrm{ml}$ ) was added to each well containing $50 \mu \mathrm{l}$ diluted serum. The results were read visually by two independent laboratory technicians (and a third technician as a tie-breaker) against a white background after $12 \mathrm{~h}$ of incubation at room temperature. Each set of samples tested were compared against a negative and a positive control. The cut-off serum dilution for the DAT was $\leq 1: 600$.

Symptomatic cases were defined as persons with (a) DAT titer of $\geq 1: 1600$ dilutions with fever for $\geq 2$ weeks not responding to usual treatment for malaria and/or the common ailments and either splenomegaly or evidence of wasting. Asymptomatic cases were those from the VL endemic areas with a positive DAT (i.e. $\geq 1: 1600$ ), but no clinical symptoms or signs and no history of prior treatment for kala-azar. Lastly the third group, were participants where the DAT titer was $<1: 600$ dilutions. Ministry of Health Uganda guidelines, states that that when DAT is $<1: 1600$ dilution, the symptoms (if present) is likely to be from other causes [11].

\section{RESULTS}

Of the 288 participants, results of 3 participants were excluded from the analysis due to incomplete information. Ten of the 59 DAT positive participants were previously successfully treated for kala-azar and 7 had symptomatic kala-azar infection. Therefore the actual prevalence of kala-azar infection in Pokot county was 17.2\% (42 asymptomatic cases plus 7 symptomatic cases of the 285 participants), while the prevalence of symptomatic kala-azar infection in the community was $2.5 \%(7 / 285)$. Therefore, the ratio of symptomatic to asymptomatic was 1:6.

In Amudat sub-county, $5.3 \%$ of the study population was DAT positive, while $14.6 \%$ and $31.9 \%$ were DAT positive in Karita and Loroo sub-counties, respectively. The Chi-square test showed that prevalence of kala-azar infection in Amudat sub-county significantly differs from Loroo and Karita sub-counties at $95 \%$ confidence interval (CI) with p-value $<0.001$ for both (Table 1).

Kala-azar prevalence was relatively high amongst males (19.9\%) compared to females (14.6\%) (Table 2), but this difference was not significant. There was also no statistically significant difference in the prevalence amongst different age groups (Table 1).
Although this study was not designed to examine the risk factors as such, it is important to report that a higher DAT positivity was noted amongst households reporting history of kala-azar treated persons compared with households without a person ever treated for kala-azar (Table 3). We also noted that DAT positivity was higher in households that had spent many months without spraying their animals. It was about 1.5 times higher in participants who reported not to have sprayed cattle in 6 or more months preceding this study compared to those who reported spraying their cattle within the last six months before the study (Table 3).

\section{DISCUSSION}

This study showed that the prevalence of kala-azar infection in Pokot county Amudat district as measured by DAT positivity was $17.2 \%$. But the prevalence of symptomatic infection in the community was $2.5 \%$ (7 of 285 ). This latter result greatly differs from the $17 \%$ that was reported as the prevalence of clinical (symptomatic) kala-azar infection in Pokot county in 2008 [12]. This could be attributed to the fact that this initial study was based on the patients attending (seeking care) at Amudat hospital. Although caution should be taken in interpretation of the low community prevalence of symptomatic kala-azar infection observed in our study in Pokot county. Consideration should be made of the fact that there is an intense community mobilization and early identification of cases that are then brought to the treatment centre. This mobilization is being undertaken by Leishmaniasis East Africa Platform (LEAP) funded by Drugs for Neglected Diseases initiative (DNDi) that is currently conducting clinical trials on a number of drugs for treating kala-azar. One may argue that it is because of this mobilization of kala-azar cases from the community that has lowered the prevalence of symptomatic kala-azar. But it is clear that kala-azar infection is widespread in this area given the overall prevalence of $17.2 \%$. Current hospital records (Amudat hospital monthly in-patient reports 2010-unpublished) also indicates that patients have come from other districts in north-east Uganda (Moroto and Kotido, all to the North of Amudat district), distant from Pokot county. Given the belief that kala-azar is largely confined within Pokot county, reported cases from other areas is a cause of concern, but perhaps this might have also contributed to the high symptomatic kala-azar infection prevalence in the hospital-based studies reported earlier at 17\% [12].

Our study also revealed that kala-azar infection was relatively higher amongst males. Of the 49 DAT positive participants, $57.1 \%$ were males; this is close to what was previously reported in $59.1 \%$ males amongst the participants in a case-control study in this area [12]. This may be attributed to males having a relatively higher chance 
Table 2. Sex distribution of KA in the three sub-counties.

\begin{tabular}{|c|c|c|c|c|c|c|c|c|c|}
\hline \multirow[b]{2}{*}{ Sex } & \multirow[b]{2}{*}{$\begin{array}{c}\text { No. } \\
\text { participants, } n\end{array}$} & \multirow{2}{*}{$\begin{array}{c}\text { Loroo } \\
\text { Total DAT } \\
\text { positives } \\
(\% \text { of } n)\end{array}$} & \multirow[b]{2}{*}{ Clinical KA } & \multicolumn{3}{|c|}{ Amudat } & \multicolumn{3}{|c|}{ Karita } \\
\hline & & & & $\begin{array}{c}\text { No. } \\
\text { participants, } \mathrm{n}\end{array}$ & $\begin{array}{l}\text { Total DAT } \\
\text { positives } \\
\text { (\% of } n)\end{array}$ & $\begin{array}{l}\text { Clinical } \\
\text { KA }\end{array}$ & $\begin{array}{c}\text { No. } \\
\text { participants, } \mathrm{n}\end{array}$ & $\begin{array}{l}\text { Total DAT } \\
\text { positives } \\
(\% \text { of } n)\end{array}$ & Clinical KA \\
\hline Male & 46 & $17(36.9)$ & 2 & 47 & $1(2.1)$ & 0 & 48 & $10(20.8)$ & 2 \\
\hline Female & 48 & $13(27.1)$ & 1 & 48 & $4(8.3)$ & 1 & 48 & $4(8.3)$ & 1 \\
\hline Total & 94 & $30(31.9)$ & 3 & 95 & $5(5.3)$ & 1 & 96 & 14 (14.6) & 3 \\
\hline
\end{tabular}

Table 3. Odd ratio and $95 \% \mathrm{CI}$ for the association DAT positivity and the independent factors.

\begin{tabular}{|c|c|c|c|c|c|}
\hline \multirow[t]{2}{*}{ Variable } & \multirow[t]{2}{*}{$\begin{array}{l}\text { Proportion of DAT } \\
\text { positive participants }\end{array}$} & \multicolumn{2}{|c|}{ Unadjusted } & \multicolumn{2}{|c|}{ Adjusted } \\
\hline & & Odds Ratio $(95 \% \mathrm{CI})$ & p-value & Odds Ratio $(95 \% \mathrm{CI})$ & p-value \\
\hline \multicolumn{6}{|l|}{ Sex } \\
\hline Female & $21 / 144$ & 1 & & 1 & \\
\hline Male & $28 / 141$ & $1.45(0.78-2.69)$ & 0.240 & $1.28(0.64-2.54)$ & 0.489 \\
\hline \multicolumn{6}{|l|}{ Sub-county } \\
\hline Amudat & $5 / 95$ & 1 & & 1 & \\
\hline Loroo & $30 / 94$ & $8.44(3.11-22.92)$ & 0.000 & $7.18(2.57-21.6)$ & $0.000^{*}$ \\
\hline Karita & $14 / 96$ & $3.07(1.06-8.90)$ & 0.039 & $2.75(0.93-8.12)$ & 0.067 \\
\hline \multicolumn{6}{|c|}{$\begin{array}{l}\text { Household member previously } \\
\text { treated for KA }\end{array}$} \\
\hline No & $49 / 263$ & 1 & & 1 & \\
\hline Yes & $10 / 22$ & $2.20(0.971-5.00)$ & 0.035 & $1.96(0.96-4.96)$ & $0.048^{*}$ \\
\hline \multicolumn{6}{|c|}{ Last insecticide spraying of cattle } \\
\hline Within last six months & $11 / 85$ & 1 & & & \\
\hline$>6$ but $<12$ months ago & $13 / 61$ & $1.82(0.76-4.39)$ & 0.182 & & \\
\hline$>12$ months ago & $25 / 139$ & $1.48(0.69-3.18)$ & 0.320 & & \\
\hline
\end{tabular}

* Statistically significant.

of getting bitten in the bush by the sand-flies, because it is male that look after animals in the bush. In addition, cattle raids are done by males and this involve travelling long distances and there are chances that they may even contract infection from the areas where they go for cattle rustling, even if in their locality there had been no history of kala-azar infection.

The prevalence of kala-azar was high in Loroo, followed by Karita and Amudat sub-counties, respectively even after stratifying by age group and sex. Although the sample size for this study was relatively small and the study not designed for risk factors assessment, the higher prevalence in Loroo and Karita sub-counties may be related to the fact that there is usually clustering of DAT positivity around active cases [13-15]. There were three clinical cases in Loroo and Karita compared to one in
Amudat. But other potential factors such as variation in bio-climatic condition, migration patterns and socio-economic status amongst these sub-counties may also be playing a role in the observed variation. But this disparity in prevalence amongst the sub-counties needs further evaluation.

The ratio of symptomatic kala-azar infection to asymptomatic infection of 1:6 implies that for every symptomatic kala-azar case there are six asymptomatic kalaazar infection cases in the community. The asymptomatic cases are usually a source (reservoirs) of kala-azar infection, and thus they continue to spread the infection in the community [13-16].

Previous study in this area reported that insecticide spraying of cattle increases the risk of kala-azar infection [12]. However, from observation in this current study, 
we suggest that spraying of animals could be protective given the lower prevalence of kala-azar infection amongst participants whose household had recently (within the last 6 months) applied insecticide to cattle. This is likely to be so, because most of the insecticides used in Pokot County are pyrethroids and in general these insecticides (pyrethroids) irritate the insects and therefore apart from killing them, it also repels them. Pyrethroids have residual effects of between 4 and 6 months. The authors in the earlier study argued that the application of insecticide to animals increased the risk of kala-azar infection due to sand-flies potentially shifting their host-seeking behaviour to humans from the animals that have been sprayed [12]. This is unlikely to be the case in the Pokot county of Uganda where the animals usually stay within the $m a$ nyatta together with the humans and the spraying of animals usually takes place within the manyatta. Given the repellent nature of the pyrethroids and its residual effects, humans are more likely to be protected from sand-fly bites if their animals are sprayed. This study therefore suggests that the transmission of kala-azar in Pokot is more likely to be anthroponotic rather than zooponotic. Cattle or other animals may be only occasional hosts where sand-flies feed when there are no humans. However, there is need for a study to confirm the presence of Leishmania antibodies in animals and getting isolates of amastigotes and characterizing them, as has been done in Sudan and Kenya [17,18].

Higher prevalence of kala-azar infection amongst household members with previous household case of kala-azar could be explained by the usual clustering of DAT positivity around active kala-azar cases $[13,19,20]$.

\section{CONCLUSION}

The overall prevalence of kala-azar infection in Pokot county at $17.2 \%$ is high, although it is also worth noting the heterogeneous distribution of kala-azar in Pokot county. Loroo sub-county which is the northern part of Pokot county bordering Moroto district has a higher prevalence. A ratio 1:6 of symptomatic to asymptomatic infection means the disease continues to spread in the community and only a small proportion of cases are being treated in the health facility and this should raise concerns.

In view of the recent report that kala-azar is occurring outside Pokot county, there is a need for a more extensive study to determine occurrence and the current risk factors of kala-azar infection in the whole of northeastern Uganda. Studies to determine the role of the animals in kala-azar transmission and the sand fly behavior in Pokot county will also be important.

Finally, the presence of kala-azar in Amudat district is an additional stress on the district health system and resources and requires additional specific control efforts to be spearheaded by ministry of health in order to relieve it.

\section{ACKNOWLEDGEMENTS}

This research was conducted in partial fulfillment of the requirements for the award of Master of Public Health degree of Makerere University, Kampala. The training was self-sponsored. Amudat hospital partially supported the research through provision of laboratory facility and reagents for direct agglutination test. We would also like to acknowledge the contribution of Associate Professor Joseph Kode-Lule and Dr Nazarius T. Mbona for the advice and ensuring quality at all the stages of the study.

\section{REFERENCES}

[1] World Health Organization (2009) Magnitude of the problem.

http://www.who.int/leishmaniasis/burden/magnitude/burd en magnitude/en/index.html

[2] Desjeux, P. (1996) Leishmaniasis. Public health aspects and control. Clinical Dermatology, 14, 417-423. http://dx.doi.org/10.1016/0738-081X(96)00057-0

[3] World Health Organization (2000) The Leishmaniasis: WHO fact sheet.

http://www.who.int/mediacentre/factsheets/fs375/en/inde x.html

[4] World Health Organization (2010) Control of the Leishmaniases: Report of the WHO expert committee meeting, Geneva. March 22-26, 2010. WHO Technical Report Series, 949, 1 .

[5] Topno, R.K., Das, V.N., Ranjan, A., Pandey, K., Singh, D., Kumar, N., Siddiqui, N.A., Singh, V.P., Kesari, S., Kumar, N., Bimal, S., Kumar, A.J., Meena, C., Kumar, R. and Das, P. (2010) Asymptomatic infection with visceral leishmaniasis in a disease-endemic area in Bihar, India. American Journal of Tropical Medicine and Hygiene, $\mathbf{8 3}$, 502-506. http://dx.doi.org/10.4269/ajtmh.2010.09-0345

[6] McKinnon, J.A. (1962) Kala-azar in the upper rift valley of Kenya. Part I. Background and discovery of the disease. Journal of Tropical Medicine and Hygiene, 65, 5153.

[7] Marlet, M.V., Sang, D.K., Ritmeijer, K., Muga, R.O., Onsongo, J. and Davidson, R.N. (2003) Emergence or reemergence of visceral leishmaniasis in areas of Somalia, north-eastern Kenya, and south-eastern Ethiopia in 200001. Transactions of the Royal Society of Tropical Medicine and Hygiene, 97, 515-518. http://dx.doi.org/10.1016/S0035-9203(03)80012-3

[8] Hayes, R.J. and Bennett, S. (1999) Simple sample size calculation for cluster-randomized trials. International Journal of Epidemiology, 28, 319-326. http://dx.doi.org/10.1093/ije/28.2.319

[9] Gouvea, V.M., Wernrck, L.G., Costa, N.H.C. and Aécio de Amorim, F.C. (2007) Factors associated to Montenegro skin test positivity in Teresina, Brazil. Acta Tropica, 104, 99-107.

http://www.sciencedirect.com/science/article/pii/S000170 
$\underline{6 \times 07001891}$

http://dx.doi.org/10.1016/j.actatropica.2007.07.010

[10] Harith, H.E., Kolk, A.H., Leewenburg, J., Muigai, R., Huigen, E., Jelsma, T. and Kager, P.A. (1988) Improvement of a direct agglutination test for field studies of visceral leishmaniasis. Journal of Clinical Microbiology, 26, 1321-1325.

[11] Ministry of Health-Uganda (2007) The diagnosis, treatment and prevention of visceral leishmaniasis in Uganda: Guidelines for clinicians and health workers. Ministry of Health, Kampala.

[12] Kolaczinski, J.H., Reithinger, R., Worku, D.T., Ocheng, A., Kasimiro, J., Kabatereine, N. and Brooker, S. (2008) Risk factors of visceral leishmaniasis in East Africa: A case-control study in Pokot territory of Kenya and Uganda. International Journal of Epidemiology, 37, 344-352. http://dx.doi.org/10.1093/ije/dym275

[13] Al-Shamahy, H.A. (1998) Sero-prevalence of Kala-Azar among Humans and Dogs in Yemen. Annals of Saudi Medicine, 18, 66-68.

[14] Ranjan, A., Sur, D., Singh, V.P., Siddique, N.A., Manna, B., et al. (2005) Risk factors for Indian Kala Azar. The American Journal of Tropical Medicine and Hygiene, 73, 74-78.

[15] Bern, C., Rashidul, H., Chowdhury, R., Ali, M., Kurkjian, K.M., Vaz, L., Amann, J., Wahed, M.A., Wagatsuma, Y., Breiman, R.F., Williamson, J., Secor, W.E and Maguire, J.H. (2007) The epidemiology of visceral leishmaniasis and asymptomatic Leishmanial infection in a highly endemic Bangladeshi village. American Journal of Tropical Medicine and Hygiene, 76, 909-914. http://www.ajtmh.org/content/76/5/909.short

[16] Fakhar, M., Motazedian, M.H., Hatam, G.R., Asgari, Q., Kalantari, M. and Mohebali, M. (2008) Asymptomatic human carriers of Leishmaniainfantum: Possible reser- voirs for Mediterranean visceral Leishmaniasis in southern Iran. Annals of Tropical Medicine and Parasitology, 102, 1-7. http://dx.doi.org/10.1179/136485908X337526

[17] Mukhtar, M.M., Sharief, A.H., El Saffi, S.H., Harith, A.E., Higazzi, T.B., Adam, A.M. and Abdalla, H.S. (2000) Detection of antibodies to Leishmania donovani in animals in a kala-azar endemic region in eastern Sudan: A preliminary report. Transactions of the Royal Society of Tropical Medicine and Hygiene, 94, 33-36. http://trstmh.oxfordjournals.org/content/94/1/33.full.pdf http://dx.doi.org/10.1016/S0035-9203(00)90429-2

[18] Dereure, J., El-Safi, S.H., Bucheton, B., Bonid, M., Kheirc, M.M., Davoustd, B., Pratlonga, F., Feugierb, E., Lamberta, M., Desseinb, A. and Dedeta, J.P. (2003) Visceral Leishmaniasis in eastern Sudan: Parasite identification in humans and dogs; host-parasite relationships. Microbes and Infection, 5, 1103-1108.

http://www.sciencedirect.com/science/article/pii/S128645 790300220X

http://dx.doi.org/10.1016/j.micinf.2003.07.003

[19] Ryan, J.R., Mbui, J., Rashid, J.R., Wasunna, M.K., Kirigi, G., Magiri, C., Kinoti, D., Ngumbi, P.M., Martin, S.K., Odera, S.O., Hochberg, L.P., Bautista, C.T. and Chan, A.S. (2006) Spatial clustering and epidemiological aspects of visceral leishmaniasis in two endemic villages, Baringo district, Kenya. American Journal of Tropical Medicine and Hygiene, 74, 308-317.

[20] Schenkel, K., Rijal, S., Koirala, S., Vanlerberghe, V., Van der Stuyft, P., Marina Gramiccia, M. and Boelaert, M. (2006) Visceral leishmaniasis in southern Nepal: A cross-sectional survey on Leishmania donovani infection and its risk factors. Tropical Medicine and international Health, 11, 1792-1799.

http://dx.doi.org/10.1111/j.1365-3156.2006.01735.x 